\title{
The Use of Visual Tests in the Screening Strategy of Cervical Dysplasies and Cervical Cancer at the Laquintinie Hospital Douala, Cameroon: A Cross-Sectional Study
}

\author{
Essome Henri ${ }^{1,2 *}$, Mve Koh Valère ${ }^{3}$, Egbe Obinchemti Thomas ${ }^{4,5}$, Engbang Jean Paul ${ }^{1,2}$, \\ Essiben Felix ${ }^{3}$, Boten Merlin'2, Tocki Toutou Grâce ${ }^{2}$, Tsetsafong Aristophane ${ }^{1}$, \\ Mboudou Emile Telesphore ${ }^{3}$
}

\author{
${ }^{1}$ Faculty of Medicine and Pharmaceutical Sciences, University of Douala, Douala, Cameroon \\ ${ }^{2}$ Laquintinie Hospital of Douala, Douala, Cameroon \\ ${ }^{3}$ Faculty of Medicine and Biomedical Sciences, University of Yaounde I, Yaounde, Cameroon \\ ${ }^{4}$ Faculty of Health Sciences, University of Buea, Buea, Cameroon \\ ${ }^{5}$ Douala General Hospital, Douala, Cameroon \\ Email: *essometocky@yahoo.com
}

How to cite this paper: Henri, E., Valère, M.K., Thomas, E.O., Paul, E.J., Felix, E., Merlin, B., Grâce, T.T., Aristophane, T. and Telesphore, M.E. (2019) The Use of Visual Tests in the Screening Strategy of Cervical Dysplasies and Cervical Cancer at the Laquintinie Hospital Douala, Cameroon: A Cross-Sectional Study. Open Journal of Obstetrics and Gynecology, 9, 1058-1072. https://doi.org/10.4236/ojog.2019.97103

Received: June 8, 2019

Accepted: July 23, 2019

Published: July 26, 2019

Copyright (๑) 2019 by author(s) and Scientific Research Publishing Inc. This work is licensed under the Creative Commons Attribution International License (CC BY 4.0).

http://creativecommons.org/licenses/by/4.0/

\section{c. (i) Open Access}

\begin{abstract}
Introduction: The prevalence of cervical cancer in Cameroon is $80.73 / 100,000$ women, with an estimated incidence of $40 / 100,000$ women-years. It is a real public health problem. There is no systematic and effective screening program for cervical cancer in our country, despite the advent of visual tests that are simple to use, low cost, and adapted to the modest income of our social groups. Objectives: We aimed at determining the usefulness and place of visual tests in screening for cervical dysplasia and cervical cancer for its implementation at the Laquintinie Hospital Douala, Cameroon. Methods: We conducted a prospective analytic cross-sectional study of cervical dysplasia and cervical cancer screening by visual testing at the Laquintinie Hospital Douala from December 1, 2016 to March 31, 2017. Data collection was by consecutive non-probabilistic method and consenting sexually active women older than 21 years were enrolled for study. Data analysis was with Epi Info ${ }^{\mathrm{TM}}$ version 7. Associations were done with the Chi square, student t-test and Fischer's exact test where appropriate. Bivariate and multivariate analysis was done and reported as odd ratios, adjusted odd ratios and $95 \%$ confidence intervals. Statistical significance was set at $P<0.05$. Results: We received 1590 women, of whom 1506 (94.7\%) screened for dysplastic lesions and cervical cancer during the study period. The results obtained were: 1417 (94.1\%) had a normal result; 64 (4.2\%) had a positive visual test (TV+); and 25 (1.7\%)
\end{abstract}


visual tests were inconclusive (TV-nC). Of the 64 women whose visual tests were positive, 15 (23.5\%) were HIV+. We performed 80 colposcopies and biopsies, including 61 women with positive visual tests and 19 non-conclusive visual tests. Among women with TV+, we found 06 cancers (squamous cell carcinoma: 05, adenocarcinoma: 01) and 05 dysplasias (CIN1: 04, CIN3: 01). Histological examination in women with TV-nC revealed 02 dysplasias (CIN1: 02). Half of the women with cervical cancer were HIV+. In our series, the prevalence of cervical dysplasia and cervical cancer was respectively 05 per 1000 women and 04 per 1000 women. The early onsets of sexual intercourse and co-infection with HIV were the main factors associated. Visual tests were very sensitive (84.62\%), but with a relatively low specificity (25.37\%). Conclusion: Visual tests prove to be a useful tool for mass screening of precancerous and cancerous lesions of the cervix in view of its sensitivity, cost and performance.

\section{Keywords}

IVA, IVL, Cervical Cancer, Sensitivity, Specificity

\section{Introduction}

In the past few years, there has been a rise in cancer incidence worldwide [1]. Cervical cancer is one of the most frequently diagnosed cancers. It is of infectious origin and has a slow evolution. It takes an average of fifteen years to develop from primary infection with human papillomavirus (HPV) oncogene to genital tropism, to the various precancerous histological lesions accompanying the persistence of the infection [2] [3].

With 528,000 new cases each year, cervical cancer is the fourth most common cancer worldwide after breast cancer, colorectal cancer and lung cancer. Its prevalence and incidence are significantly higher (nearly $70 \%$ of the global burden) in low-resource countries, particularly in sub-Saharan Africa and Asia [1]. It is also the fourth leading cause of cancer deaths $(266,000$ deaths in 2012, or 30 women per hour) among women worldwide [2]. Depending on the region, the highest incidence of cervical cancer occurs in Africa with 30.7 invasive cancers per 100,000 women [4]. Then comes the Southeast Asian region with 24.4 invasive cancers per 100,000 women [4]. The lowest incidence is in the Middle East with 9.0 invasive cancers per 100,000 women [4]. In Cameroon, it is the second most common gynaecological cancer after breast cancer and the leading cause of cancer death in women [5] [6]. According to GLOBOCAN 2012, the prevalence of cervical cancer in Cameroon is 80.73/100,000 women, with an estimated incidence of 40/100,000 women-years [1]. The average age at diagnosis is 49 years [7]. Because of these numbers, cervical cancer is a social scourge and therefore a thorny public health problem. Organized screening of cervical cancer by cytology has allowed in developed countries to significantly reduce the incidence and mortality of this cancer [8] [9]. In Cameroon, as in other developing countries, 
the incidence of cervical cancer remains high and the stage of the disease is advanced at the time of diagnosis [9]. In most low-income countries, there is no systematic and effective cervical cancer screening programs, screening is selective, opportunistic or sporadic in the form of campaigns. Added to these are insufficient financial resources, weak health systems and limited number of practitioners [10]. This largely explains the high prevalence and mortality rates of cervical cancer [10]. Faced with these difficulties, it became imperative to design new screening methods, an alternative to conventional cytology. This method should be simpler to handle, and to interpret, and sensitive and specific, and cheap and can be used at all levels of the health pyramid. Hence there is the establishment of visual tests (VT): visual inspection with acetic acid (VIA) and visual inspection with Lugol iodine (VILI).

Among the various cervical cancer screening techniques, VIA and VILI is a simple and inexpensive screening method [11]. It has been validated and recommended by the World Health Organization (WHO) as an alternative method to conventional Papanicolaou smears in screening for cervical cancer in poor countries [8]. Its performance has been evaluated compared to the conventional smear by several studies conducted around the world [12] [13] [14] [15]. The lack of implementation and popularization of this method in our health area motivated us to conduct this study to determine the real place of visual tests, as an alternative to conventional cytology in detecting dysplasia and cervical cancer in a population of women attending the Laquintinie Hospital Douala.

\section{Materials and Methods}

We conducted a prospective cross-sectional study at the Department of Obstetrics and Gynaecology of the Laquintinie Hospital Douala from December 1, 2016 to March 31, 2017. We enrolled consenting sexually active women aged 21 years and above into study. Women who were in their menses and those receiving treatment for cervical cancer, or pregnant women in the second trimester of pregnancy and those who did not sign informed consent/assent forms were excluded from study.

Information concerning cervical cancer screening was broadcasted over the media (local radio station, television and press release) highlighting the benefits of early detection of cervical cancer.

\subsection{Sampling and Sample Size Determination}

\section{Study population}

The study population comprised of women who consulted the obstetrics and Gynaecology department of the Laquintinie Hospital Douala.

\section{Sample size calculation}

Epi-Info version 7.1.3.0 statistical software was used to calculate the sample size by using single population proportion formula with the assumption of proportion $(P)$ for prevalence of precancerous lesion of the cervix by VIA and VILI technique in the North region of Cameroon of $12.7 \%(P=0.127)$ by Kalgong $\mathrm{G}$ 
et al., 2017 [1]; 95\% CI with 5\% tolerable error and design effect of 1.5 (i.e. a strategy of incorporating sampling weights and the design variables into the analysis to avoid errors in inference in complex sampling schemes).

Therefore Lorenz formula was used [2].

$$
N=D E F F \times \frac{Z^{2} \times P(1-P)}{d^{2}}
$$

where

$N=$ study population;

$1.96=Z$ value for $P=0.05 \%$ or $95 \%$ confidence limits;

$P=$ Estimated prevalence of precancerous lesions $(P=0.127)[1]$;

$d=$ Desired precision (5\%, i.e. 0.05$)$;

$D E F F=$ Design effect (1.5) [2].

So

$$
N=\frac{1.5 \times 1.96^{2} \times(0.127)(1-0.127)}{0.05^{2}}=255.5
$$

A minimum of 256 participants was required for study.

\subsection{Study Procedure}

Ethical clearance for study was obtained from the ethics committee of the University of Douala. Thereafter, the data collection form (questionnaire) was pretested on 15 subjects from a different population for content validity. Signed informed consent forms were obtained from enrolled participants and an interviewer administered questionnaire was used to obtain information regarding: socio-demographic data, age at first sexual intercourse, last normal menstrual period, number of sexual partners, history of sexually transmitted infection, HIV status (human immunodeficiency virus), type of family planning method used, history of smoking, previous cervical cancer screening and participants' knowledge of cervical cancer.

Our team of three gynaecologists conducted the visual inspection and acetic acid (VIA) and visual inspection and Lugol iodine (VILI) screening methods in order to minimize reading bias.

The participants were individually installed in a gynaecological position on the examination table in a consultation box. We inserted a speculum lubricated with distilled water into the vagina with visualisation assured by a portable light source. Cervical cleansing with sterile cotton was carried out with long-tongs forceps. We inspected the cervix to detect any direct anomaly and identify the squamous-columnar junction (SCJ) before application of different solutions. A cotton pad soaked into acetic acid solution diluted at $5 \%$ was applied on the cervix (SCJ) and inspection of the cervix was done one minute later and was reported on the survey card of the participant.

Two key elements were sought when reading after application of 5\% acetic acid: the squamous-columnar junction (SCJ) and the presence of an acidophilic lesion in the transformation zone (TZ). Four eventualities were possible:

- Absence of acidophilic lesion in the TZ and visible SCJ: normal result; 
- Acidophilic lesion in TZ and visible SCJ: positive result;

- Acidophilic lesion in ZT and JPC not visible: positive result;

- Absence of acidophilic lesion in TZ and SCJ not visible: inconclusive result (in postmenopausal women with cervical atrophy).

After the VIA, we proceeded to conduct VILI (second stage of the examination). A cotton swab soaked in Lugol iodine solution (VILI) was applied to the cervix and inspection done after one minute and results were reported on the survey form. This is how it was considered:

- VILI negative: if squamous epithelium became mahogany brown and the columnar epithelium does not change colour or irregular areas.

- Positive VILI: if there were clearly defined yellow areas of non-uptake of iodine affecting the SCJ or well-defined bright yellow areas of non-absorption of iodine close to the orifice if the SCJ was not visible or covering the entire cervix.

Visual tests were considered positive, if the VIA and/or VILI were positive, and negative if the SCJ was visible with VIA and VILI negative.

In case of positive visual tests or inconclusive results, colposcopy-directed biopsy of the SCJ was performed using a biopsy forceps. Post-biopsy haemostasis was assured with a dry buffer. The sample (preserved formalin) was sent histo-pathologic analysis.

\subsection{Data Management and Statistical Analysis}

The data were coded and double entered into a pre-designed template in Epi data, and analysed with Epi-Info ${ }^{\mathrm{TM}}$ version 7.1.5. Analysis focused on the usefulness and real place of visual tests in screening for dysplasia and cervical cancer for its implementation at the Laquintinie Hospital Douala. In computing the socio-demographic characteristics of study participants, measures of central tendencies like age, were expressed as means with standard deviations [SD] or medians with interquartile ranges [IQR]. Categorical variables (level of education, religion, marital status, occupation etcetera) were expressed as frequencies and percentages.

Cervical dysplasia and cervical cancer in this study were the outcome variables and a composite of indicators (age at first sexual intercourse, number of sexual partners) were the predictor variables.

The Chi squared, student t-test and Fischer's exact test (where appropriate) were used to test for associations between predictor variables and outcome variables. Binary logistic regression was used to measure the level of association and multiple logistic regressions were computed to control for confounders. Results were reported as Odds ratios (OR), adjusted Odds ratios (aOR) and their 95\% confidence intervals (CI). Measure of association was considered statistically significant at a two-tailed $P$-value when $P<0.05$.

\section{Results}

\subsection{Sociodemographic Variables}

During our study period, we received 1590 women, and screened 1506 women 
according to our inclusion criteria.

The average age was $40 \pm 12$ years; IQR 21 to 79 years and majority participants were in the age group 30-39 years (Figure 1).

About $40.6 \%$ participants were married and $41.8 \%$ were single. Almost half, $47 \%$ (708/1506) participants had secondary level education while 55\% (829/1506) had a low socioeconomic level. Low socioeconomic level based on the minimum wage in our setting (Cameroon) was considered having a revenue between 36,000 FCFA and <150,000 FCFA, average having between 150,000 FCFA and 350,000 FCFA, and high having >350,000 FCFA (Table 1).

\subsection{Risk Factors}

In the study of risk factors, $40.2 \%(608 / 1506)$ had their first intercourse before, 18 years, $11.6 \%(175 / 1506)$ were grand multiparous women, $26.6 \%(401 / 1506)$ used family planning methods mainly condom (51.4\% [206/401]) or 13,6\% [206/1506]). Furthermore, 0.7\% (10/1506) participants were tobacco users and 23.6\% were positive for C. trachomatis while 5.7\% (86/1506) where HIV positive. All study participants did not receive HPV vaccination and 96.3\% (1450/1506) had no Knowledge of cervical cancer (Table 2 \& Table 3 ).

\subsection{Statistical Analysis}

Of 1506 screened, 64 (4.2\%) visual tests were positive. We performed $4.05 \%$ (61/1506) colposcopy-directed biopsies and histopathology reported six $(0.4 \%)$ positive reports among which one $(0.07 \%)$ carcinoma in-situ and five $(0.33 \%)$ cervical dysplasia. Among the participants with inconclusive visual tests; 19 colposcopy-directed biopsies were performed and two $(0.13 \%)$ dysplasia (CIN1) were reported on histopathology (Figure 2).

After statistical analysis, we had a sensitivity $=$ Sensitivity $=$ true positive/true positive + false negatives $11 / 13=0.846=84.6 \%(95 \%$ CI: $54.55-98.08)$ and a

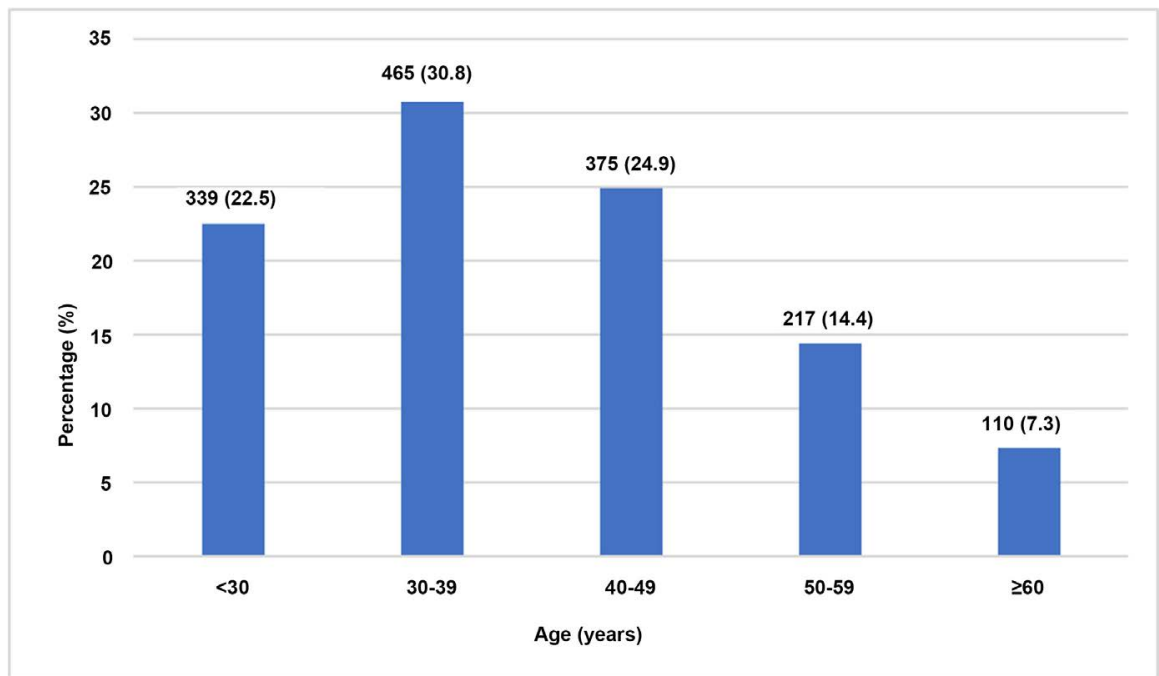

Figure 1. Distribution of women by age group. 
Table 1. Sociodemographic characteristics of the study population.

\begin{tabular}{cccc}
\hline Variables & & $\begin{array}{c}\text { Frequency } \\
N=1506\end{array}$ & Percentage \\
\hline Marital status & Married & 612 & 40.6 \\
& Single & 629 & 41.8 \\
& Divorced & 22 & 1.5 \\
& Widow & 243 & 16.1 \\
Level of education & None & 27 & 1.8 \\
& Primary & 272 & 18.1 \\
& Secondary & 708 & 47.0 \\
& Higher education & 499 & 33.1 \\
& Low & 829 & 55.0 \\
Socio-economic level & Average & 673 & 44.7 \\
& High & 4 & 0.3 \\
\hline
\end{tabular}

Table 2. Gynaecological and obstetric history.

\begin{tabular}{cccc}
\hline Variables & & $\begin{array}{c}\text { Frequency } \\
N=1506\end{array}$ & Percentage \\
\hline $\begin{array}{c}\text { Age at first sexual } \\
\text { intercourse (years) }\end{array}$ & $<18$ yrs. & 608 & 40.4 \\
& $\geq 18$ Ys & 898 & 59.6 \\
Gestation & 0 & 200 & 13.3 \\
& 1 & 177 & 11.8 \\
& $2-4$ & 730 & 48.5 \\
& $\geq 5$ & 399 & 26.5 \\
Parity & 0 & 286 & 19.0 \\
& 1 & 250 & 16.6 \\
& $2-4$ & 795 & 52.8 \\
& $\geq 5$ & 175 & 11.6 \\
Contraceptives & No & 1105 & 73.4 \\
& Yes & 401 & 26.6 \\
Condom & Yes & 206 & $(13.70 \%)$ or $51.4 \%$ \\
& No & 195 & $(12.95 \%)$ or $48.6 \%$ \\
\hline
\end{tabular}

specificity $=$ specificity $=$ true negatives/false positives + true negatives $17 / 67=$ $0.253=25.3 \%$ (95\% CI: 15.53 - 37.49) (Table 4).

Tertiary level of education (AOR 0.05; 95\% CI: $0.01-0.37, P=0.003$ ) was statistically protective of cervical dysplasia and cervical cancer (Table 5). In the multivariate analysis HIV positive status (AOR 10.7; 95\% CI $3.12-33.87, P<$ 0.0001 ) and coitarche before 18 years (AOR 8.24; 95\% CI: $2.04-54.92, P=0.002$ were factors significantly associated with cervical dysplasia and cervical cancer (Table 6). 
Table 3. Personal history.

\begin{tabular}{cccc}
\hline Variables & & Frequency & Percentage \\
\hline \multirow{2}{*}{ Tobacco smoking } & No & 1496 & 99.3 \\
Knowledge of cervical cancer & Yes & 10 & 0.7 \\
& No & 1450 & 96.3 \\
Previous vaccination & Yes & 56 & 3.7 \\
& No & 1506 & 100 \\
Co-morbidities & Yes & 00 & 00 \\
& HIV & 86 & 5.7 \\
& Chlamydia & 356 & 23.7 \\
& Syphilis & 32 & 2.1 \\
& Herpes & 22 & 1.5 \\
\hline
\end{tabular}

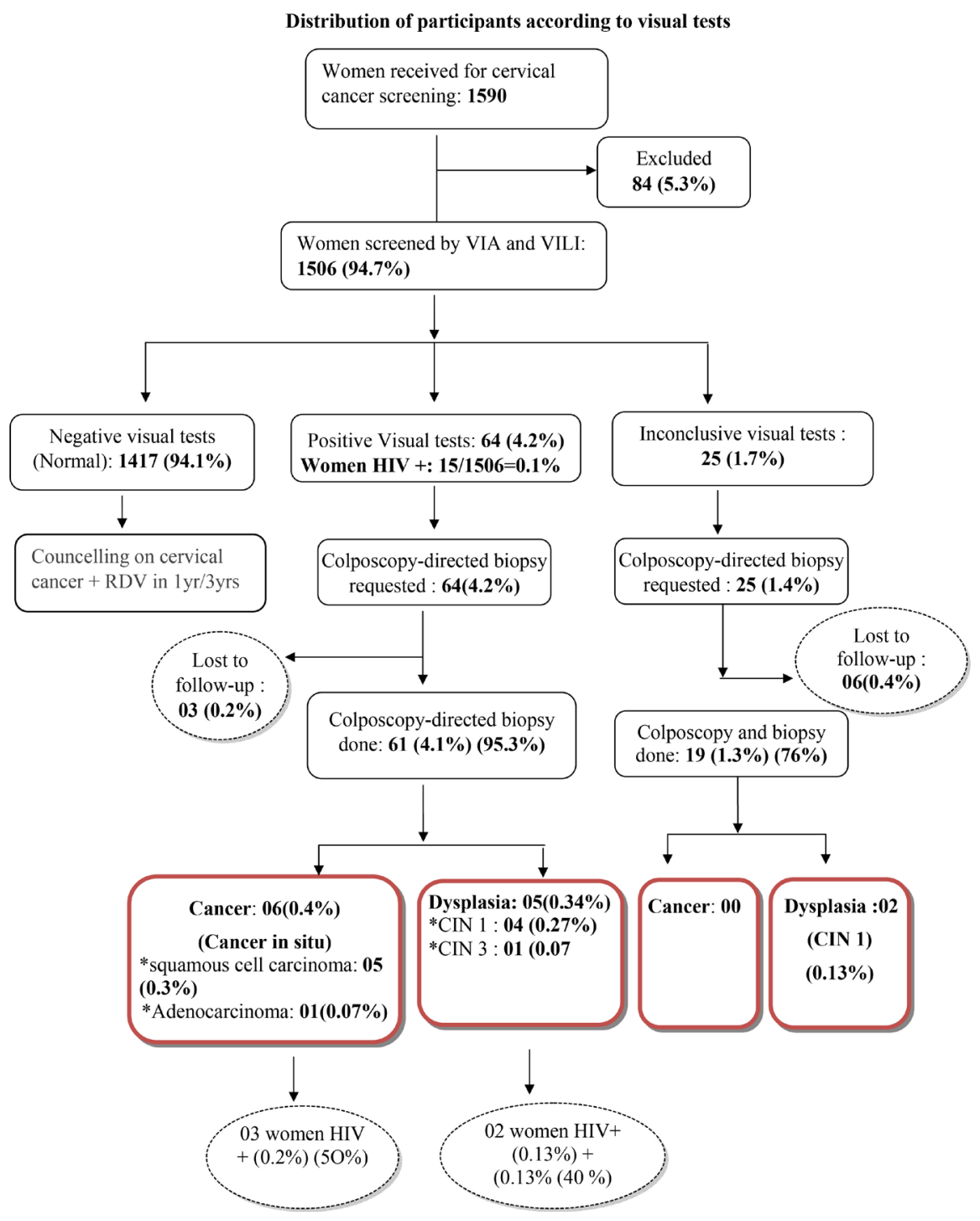

Figure 2. Breakdown of participants by visual tests. 
Table 4. Sensitivity and specificity of visual tests.

\begin{tabular}{ccccc}
\hline & & \multicolumn{3}{c}{ Biopsy $N=61$} \\
\cline { 3 - 5 } & & Positive & Negative & Total \\
\hline \multirow{2}{*}{$\begin{array}{c}\text { Visual } \\
\text { tests }\end{array}$} & Positive & $11(13.75)$ & $50(62.5)$ & $61(76.25)$ \\
& Negative & $2(2.5)$ & $17(21.25)$ & $19(23.75)$ \\
& Total & $13(16.25)$ & $67(83.75)$ & $80(100)$ \\
\hline
\end{tabular}

Table 5. Socio-demographic profile of patients with dysplasia or cervical cancer.

\begin{tabular}{|c|c|c|c|c|c|}
\hline & & Normal & $\begin{array}{c}\text { Cancer/ } \\
\text { Dysplasia }\end{array}$ & AOR $(95 \% \mathrm{CI})$ & $P$ \\
\hline & & N (\%) & N (\%) & & \\
\hline \multirow[t]{5}{*}{ Age } & $<30$ & $338(99.7 \%)$ & $1(0.3 \%)$ & $0.29(0.04-2.19)$ & 0.319 \\
\hline & $30-39$ & $461(99.1 \%)$ & $4(0.9 \%)$ & $2.93(0.33-26.36)$ & 0.337 \\
\hline & $40-49$ & $371(98.9 \%)$ & $4(1.1 \%)$ & $3.64(0.41-32.77)$ & 0.248 \\
\hline & $50-59$ & 215 (99.1\%) & $2(0.9 \%)$ & $3.14(0.28-34.89)$ & 0.351 \\
\hline & $\geq 60$ & $108(98.2 \%)$ & $2(1.8 \%)$ & $6.26(0.56-69.71)$ & 0.136 \\
\hline \multirow[t]{2}{*}{ Married } & No & $607(99.2 \%)$ & $5(0.8 \%)$ & & \\
\hline & Yes & $886(99.1 \%)$ & $8(0.9 \%)$ & $0.91(0.30-2.80)$ & 0.873 \\
\hline \multirow{4}{*}{$\begin{array}{l}\text { Level of } \\
\text { education }\end{array}$} & None & $25(92.6 \%)$ & $2(7.4 \%)$ & $10.67(2.2-50.7)$ & 0.021 \\
\hline & Primary & $269(98.9 \%)$ & $3(1.1 \%)$ & $0.14(0.02-0.87)$ & 0.035 \\
\hline & Secondary & $702(99.2 \%)$ & $6(0.8 \%)$ & $0.11(0.02-0.56)$ & 0.008 \\
\hline & Tertiary & $497(99.6 \%)$ & $2(0.4 \%)$ & $0.05(0.01-0.37)$ & 0.003 \\
\hline \multirow[t]{2}{*}{$\begin{array}{l}\text { Socio-economic } \\
\text { status }\end{array}$} & Low & $820(98.9 \%)$ & $9(1.1 \%)$ & & \\
\hline & Average/high & $673(99.4 \%)$ & $4(0.6 \%)$ & $0.54(0.17-1.77)$ & 0.309 \\
\hline
\end{tabular}

\section{Discussion}

\subsection{Sociodemographic Data}

The average age of our series was $40 \pm 12$ years; with extremes of 21 years and 79 years.

Our mean age was like those reported in the literature by Kemfang in Cameroon in 2014 (41.0 \pm 10.7 years) [15] and Mpiga in Gabon (39.9 \pm 10.5 years) [16].

The age groups of 30-39 and 40-49 years were mostly represented in our sample.

This finding from our study is consistent with the WHO recommendations targeting women aged 35 to 45 in organized cervical cancer screenings in countries without a program [17] (Figure 1).

In our series, $40.6 \%$ of women were married and $41.8 \%$ were single (Table 1 ).

Our findings contrast with $76.9 \%$ of brides in the Kalgong study in the North-Cameroon region [18]. This high difference could be explained by the 
Table 6. Factors associated with precancerous and cancerous cervix lesions.

\begin{tabular}{|c|c|c|c|c|c|}
\hline & & Normal & Cancer/Dysplasia & $\operatorname{AOR}(95 \% \mathrm{CI})$ & $P$ \\
\hline & & $\mathrm{N}(\%)$ & $\mathrm{N}(\%)$ & & \\
\hline \multirow[t]{2}{*}{ Condom } & No & $1234(99.1 \%)$ & $11(0.9 \%)$ & & \\
\hline & Yes & $259(99.2 \%)$ & $2(0.8 \%)$ & $0.86(0.13-3.51)$ & 0.9 \\
\hline \multirow{3}{*}{$\begin{array}{c}\text { Sexual } \\
\text { intercourse } \\
\text { before } 18 \text { years }\end{array}$} & & & & & \\
\hline & No & $896(99.8 \%)$ & $2(0.2 \%)$ & & \\
\hline & Yes & $597(98.2 \%)$ & $11(1.8 \%)$ & $8.24(2.04-54.92)$ & 0.002 \\
\hline \multirow[t]{2}{*}{$\mathrm{HIV}+$} & No & $1411(99.4 \%)$ & $8(0.6 \%)$ & & \\
\hline & Yes & $82(94.3 \%)$ & $5(5.7 \%)$ & $10.7(3.12-33.87)$ & $<0.0001$ \\
\hline \multirow[t]{2}{*}{ Menopause } & No & $1135(99.2 \%)$ & $9(0.8 \%)$ & & \\
\hline & Yes & $358(98.9 \%)$ & $4(1.1 \%)$ & $1.41(0.43-4.60)$ & 0.570 \\
\hline \multirow[t]{4}{*}{ Gestation } & 0 & $200(100 \%)$ & 0 & l & l \\
\hline & 1 & $176(99.4 \%)$ & $1(0.6 \%)$ & $0.42(0.14-1.25)$ & 0.867 \\
\hline & $2-5$ & $724(99.2 \%)$ & $6(0.8 \%)$ & $1.09(0.37-3.28)$ & 0.648 \\
\hline & $\geq 6$ & $393(98.5 \%)$ & $6(1.5 \%)$ & $1.6(0.21-12.41)$ & 0.119 \\
\hline \multirow[t]{4}{*}{ Parity } & 0 & $286(100 \%)$ & 0 & l & l \\
\hline & 1 & $247(98.8 \%)$ & $3(1.2 \%)$ & $0.43(0.18-2.41)$ & 0.463 \\
\hline & $2-5$ & $788(99.1 \%)$ & $7(0.9 \%)$ & $0.66(0.32-2.86)$ & 0.939 \\
\hline & $\geq 6$ & $172(98.3 \%)$ & $3(1.7 \%)$ & $0.96(0.12-1.59)$ & 0.185 \\
\hline
\end{tabular}

early marriages in this region of Cameroon. The level of education of our respondents was mainly beyond the primary cycle, with $47.0 \%$ in secondary school and $33.1 \%$ in university (Table 2).

This proportion is like that reported by Mpiga et al. in Gabon, $44 \%$ and 31\% respectively [16]. The urban setting in which our study took place, justifies this high rate of schooling.

However, despite this relatively satisfactory level of survey respondents, less than $4 \%$ had accurate knowledge about cervical cancer. $33.8 \%$ of participants had never heard of cervical cancer. From this we conclude that cervical cancer remains a pathology unknown to the study population (Table 3).

Mahdaosui et al. in Morocco in 2012 found 75.5\% [19]. This divergence of data is due to the rural setting of this Moroccan study. Low socioeconomic status is a risk factor for cervical cancer because it promotes promiscuity, early sexual intercourse, and sometimes vagabond sex [20] [21].

\subsection{Gynaecological and Obstetrical History}

More than a third of our series (608 women or $40.4 \%$ ) had their first sexual intercourse before the age of 18 years. Mean age at first intercourse was $18 \pm 3$ years, with extremes of 09 years and 34 years. 
Our findings are like those reported by Kabibou et al. in Benin, who were $17.54 \pm 2.45$ years at first intercourse; 10 years and 29 years were the extremes [22]. Our findings reveal an increased risk of developing cervical dysplasia and motivate an advancement of age at the diagnosis of precancerous and cancerous cervical lesions [20] [21].

The mean gravidity was $4 \pm 3$, with extremes of 0 and 15 . The mean parity was $3 \pm 2$, and the extremes 0 and 12. It is like that reported by Mpiga et al. in Gabon, with average parity of $3.4 \pm 2.6$ and extremes of 0 and 12 [16]. The low proportion of women (26.6\%) using contraceptives among our respondents could justify these figures (Board).

In our population, 496 women (33\%) had a history of STIs and $86(5.7 \%)$ were HIV-positive. This rate is relatively higher than the $3.1 \%$ of seropositivity reported by Kemfang [15] and 4\% of national prevalence among Cameroonian women according to the Demographic and Health Survey 2011 [23].

The smoking rate in our population was $0.7 \%$. This rate is well below $8.4 \%$ of the Pefura et al. study in Yaoundé [24]. Exposure to warm ocean currents and the low vegetation cover of the city of douala makes it a city with suffocating heat. This contrasts with the cold climate of Yaoundé, which is conducive to tobacco addiction (Table 3 ).

\subsection{Histological Data}

Our study revealed a $4.2 \%$ incidence of positive visual test lesions. Kemfang et al. at Bethesda Hospital in Yaounde in 2014 [15] and Akinola et al. in Nigeria found a visual test positivity rate of $6.4 \%$ [15] and $16.2 \%$ [25]. The high frequency of anomalies in their studies seems to be related to the small size of their sample (421 cases and 182 cases respectively). On the other hand, our results are like those of Tietchou et al. in north-western Cameroon (1248 cases) which found $4.89 \%$ positive lesions in visual tests [26].

The frequency of positive visual test lesions among HIV-positive women was $23.4 \%$ with an ODD ratio of 10.7 (3.12 - 33.87/with $P$ value $<0.0001)$. HIV infection is the breeding ground for dysplasia and cancer of the cervix, our results confirm the data from the literature (Table 6).

The prevalence of dysplasia and cervical cancer in our series is respectively 05 per 1000 women and 04 per 1000 women, for a cumulative prevalence of dysplasia and cancer estimated at 01 per 100 women. This frequency is similar to that found in Bafang in Cameroon by Robyr et al., whose cervical smear screening reported a frequency of cervical dysplasia estimated at 1.6 per 100 women [27].

Our findings are discordant with those of Kalgong et al. in North Cameroon and Kabibou et al. in Benin reporting $12.7 \%$ and $6.3 \%$ of dysplasia of the cervix after screening by visual tests [18] [22]. The enrolment rate in our sample $(80.1 \%$ with at least one level of secondary education) seems to compensate for the precocity of their sexuality. Anything that reveals that education is therefore a political lever to fight cervical cancer. 
During this organized screening of cervical cancer at the HLD we found a sensitivity of $84.6 \%$ (95\% CI: 54.55 - 98.08) and a specificity of $25.37 \%$ (95\% CI: 15.53 - 37.49). Visual tests therefore appeared in our study to be very sensitive and not very specific (Table 4). Our findings are closer to the sensitivity of the studies carried out around the world: $45 \%$ to $79 \%$ [21].

But Kalgong et al. in North Cameroon and Mpiga et al. in Gabon found a sensitivity and specificity of 93.58 and 97.01 [18] and of $100 \%$ and $92 \%$ [16]. However, the major problem in detecting dysplasia and cervical cancer remains the subjectivity of the results. Hence there is an emphasis on the organization of continuous training in the manipulation and interpretation of visual tests. Because our team consisted exclusively of gynaecologists.

In our series, visual tests had a limit in postmenopausal women whose cervices were atrophied. Colposcopy coupled with biopsy performed in the latter allowed to detect two mild dysplasia. These figures call us to always carry out a complementary examination in case of inconclusive visual test.

The general characteristics of patients with known cervical cancer have been identified. The average age of patients with cervical cancer was $43 \pm 11$ years, with extremes of 33 years and 69 years. The most represented segment was women aged 30 to $49(61.5 \%)$. This result is similar to that found by Tebeu et al. with an average age of $41.59 \pm 7.04$ years [28] and close to the mean age at diagnosis of cervical cancer in Cameroon (49 years) [1]. We note that cervical cancer affects younger cameroonian women. Early onset of sexual intercourse and co-infection with HIV were the major determinants in the occurrence of cervical cancer with an ODDs Ratio of 8.24 (2.04 - 54.92, 95\% CI, $P$ value: 0.002$)$ and 10.7 (3.12 - 33.87, IC $=95 \% P<0.0001)$ respectively. The educational level, however, appeared to be a protective factor. These data are consistent with the literature [29] (Table 6).

Dysplastic patients had the same characteristics with some differences. The average age of the latter was $32 \pm 9$ years with extremes ranging from 23 years old to 55 years old. Our figures are like those found by Kabibou et al. in Benin (32 \pm 10.8$)$ [22] (Table 5).

Our study had two major limitations which were; the subjective nature of readings about clinical aspects of the visual tests and the recruitment of patients at $8-10^{\text {th }}$ day of menstrual cycle which is out of the ideal period of glycogen secretion.

These results justify the recommendations of the rosmand group of the Swiss society of gynaecology-obstetrics (GRSSGO), which stipulate that screening for dysplasia and cancer of the cervix begins early in the young woman from the age of 21, which regardless of age at first intercourse [30] [31] [32].

\section{Conclusion}

The prevalence of dysplasia and cervical cancer is relatively low in our study, and the early onsets of first intercourse and HIV co-infection were identified as 
associated factors. A high sensitivity was found in visual tests justifying their implementation for mass screening despite low specificity.

\section{Knowledge Prior to the Study}

- Cervical cancer is a viral disease;

- The screening is easy and the cure certain at early stages;

- Primary prevention exists by means of vaccine.

\section{What This Study Brings}

It confirms the usefulness of visual tests in a mass screening strategy in our low-income countries.

It motivates and justifies its implementation in the gynaecology department of Laquintinie Hospital as well as its popularization.

\section{Conflicts of Interest}

The authors declare no conflict of interest.

\section{Contributions of the Authors}

Essome: data collection, manuscript design and co-director of the study; Tsetsafon: data collection; Mve, Egbe, Egbang, Essiben, Boten, Tocki: Reading and correction of the manuscript; Mboudou: supervision of the writing of the manuscript, correction and director of the study.

\section{References}

[1] World Health Organization (2012) GLOBOCAN 2012: Estimated Cancer Incidence, Mortality and Prevalence Worldwide in 2012.

http://globocan.iarc.fr/pages/fact_sheets_cancer.aspx

[2] Arbyn, M., Raifu, A.O., Autier, P. and Ferlay, J. (2007) Burden of Cervical Cancer in Europe: Estimates for 2004. Annals of Oncology, 18, 1708-1715. https://doi.org/10.1093/annonc/mdm079

[3] Baseman, J.G. and Koutsky, L.A. (2005) The Epidemiology of Human Papillomavirus Infections. Journal of Clinical Virology, 32, S16-S24. https://doi.org/10.1016/j.jcv.2004.12.008

[4] Ferlay, J., Shin, H.R., Bray, F., Forman, D., Mathers, C. and Parkin, D.M. (2010) Estimates of Worldwide Burden of Cancer in 2008: GLOBOCAN 2008. International Journal of Cancer, 127, 2893-2917. https://doi.org/10.1002/ijc.25516

[5] Enow-Orock, G., Mbu, R., Ngowe, N.M., Tabung, F.K., Mboudou, E., Ndom, P., et al. (2006) Gynecological Cancer Profile in the Yaoundé Population, Cameroon. CMCH, 3, 437-444.

[6] Tebeu, P.M., Petignat, P. and Mhawech-Fauceglia, P. (2009) Gynecological Malignancies in Maroua, Cameroon. International Journal of Gynecology \& Obstetrics, 104, 148-149. https://doi.org/10.1016/j.ijgo.2008.09.005

[7] Mbakop, A., Yomi, J., Ankeum, J. and Mouelle Sone, A. (1997) Localisation des cancers chez les hommes et les femmes âgés de plus de 50 ans au Cameroun. Bulletin du Cancer, 84, 1119-1122. 
[8] WHO (2013) WHO Guidelines for Screening and Treatment of Precancerous Lesions for Cervical Cancer Prevention.

[9] Boulanger, J.C. and Gondry, J. (1996) De la bonne pratique du dépistage du cancer du col utérin. Références en Gynécologie obstétrique, 4, 75-84.

[10] World Health Organization (2015) Approche globale de prévention et de lutte contre le cancer du col de l'utérus: Vers une meilleure santé pour les femmes et les jeunes filles. http://www.who.int/iris/bitstream/10665/85342/1/9789242505146_fre.pdf

[11] Katz, I.T. and Wright, A.A. (2006) Preventing Cervical Cancer in the Developing World. The New England Journal of Medicine, 354, 1110. https://doi.org/10.1056/NEJMp068031

[12] Doh, A.S., Nkele, N.N., Achu, P., Essimbi, F., Essame, O. and Nkegoum, B. (2005) Visual Inspection with Acetic Acid and Cytology as Screening Methods for Cervical Lesions in Cameroun. International Journal of Gynecology \& Obstetrics, 89, 167-173.

[13] Wesley, R., Sankaranarayanan, R., Mathew, B., Chandralekha, B., AyshaBeegum, A., Amma, N.S., et al. (1997) Evaluation of Visual Inspection as a Screening Test for Cervical Cancer. British Journal of Cancer, 75, 436-440. https://doi.org/10.1038/bjc.1997.72

[14] Tebeu, P.M., Sandjong, I., Nkele, N., Fokoua, S., Achu, P., Kouam, L., et al. Lésions précancéreuses du col utérin en zone rurale: Etude transversale. Médecine Afr Noire, 52, 27-31.

[15] Kemfang, J.D., Ngassam, A., Ngo Um Meka, E., Tsuala, J.F., Tagne, J.C., Sando, Z., et al. (2015) Cervical Cancer Screening by Visual Inspection of the Cervix after Application of Acetic Acid (VIA) in Yaoundé, Cameroon. Health Sciences and Diseases, 16. http://www.hsd-fmsb.org/index.php/hsd

[16] Mpiga, É., et al. (2015) Interest in Visual Inspection with Acetic Acid and Lugol Iodine with Colposcope in Screening of Cervical Lesions in Gabon. Pan African Medical Journal, 22, 165. https://doi.org/10.11604/pamj.2015.22.165.7038

[17] WHO (2014) DÃ Cancer Screening Cervical Uterine Rus. In: The Fight against Cancer of the Cervix Uterine Rus, Guide to Essential Practice, WHO, 83-133.

[18] Kalgong, G., et al. (2017) Sensitivity and Specificity of Visual Inspection with Acetic Acid (VIA) and with Lugol Iodine (VILI) in the Diagnosis of Cervical Cancer in the Northern Region of Cameroon. International Biological and Biomedical Journal, 3, 66-72.

[19] Mahdaoui, E. (2012) Facteurs d'adhésion au dépistage du cancer du sein et du col utérin aux préfectures médicales de rabat et skhirat témara.

[20] Goldie, S., Gaffikin, L., Goldhaber-Fiebert, J., Gordillo-Tobar, A., Levin, C., Mahe, C. and Wright, T. (2005) Cost Effectiveness of Cervical Screening in Five Developing Countries. The New England Journal of Medicine, 353, 2158-2168. https://doi.org/10.1056/NEJMsa044278

[21] Cervical Cancer Action Coalition. Nouvelles options de dépistage et de traitement du cancer du col: 3-4.

[22] European Scientific Journal December 2015 Edition Vol. 11, No. 36.

[23] Enquête démographique et de santé et à indicateurs multiples du Cameroun, 2012. https://dhsprogram.com/pubs/pdf/FR260/FR260.pdf

[24] Pefura-Yone, E.W., et al. (2016) Prévalence et Facteurs Associés au Tabagisme à Yaoundé, Cameroun. Health Sciences and Diseases, 17. 
http://www.hsd-fmsb.org

[25] Akinola, O.I., Fabamwo, A.O., Oshodi, Y.A., Banjo, A.A., Amma, N.S. and Nair, M.K. (2007) Efficacy of Visual Inspection of the Cervix Using Acetic Acid in Cervical Cancer Screening: A Comparison with Cervical Cytology. Journal of Obstetrics and Gynaecology, 27, 703-705. https://doi.org/10.1080/01443610701614421

[26] Tietchou, S., Sando, Z., Tebeu, P.M., Sone, M., Essame Oyono, J.L. and Doh, A.S. (2015) Evaluation of the Prevention and Treatment of the Precancerous Lesions of the Uterine Cervix According to the "See and Treat" Approach. Health Sciences and Diseases, 16. http://www.hsd-fmsb.org

[27] Robyr, R. (2002) Etude pilote de dépistage du cancer du col de l'utérus dans une région rurale camerounaise. Thèse de médecine, No. Méd: 10292, Genève, 53-58.

[28] Tebeu, P.M., Sando, Z., Ndoumba, A., Sandjong, I., Mawech-Fauceglia, P. and Doh, A.S. (2013) Prevalence and Geographical Distribution of Precancerous Lesions of Uterine Cervix in Cameroun. Journal of Cytology and Histology, 4, 183.

[29] Référentiel de pratiques pour la prévention et le dépistage du cancer du col de l'utérus, juin 2013.

[30] Navarria, I. and Jacot-Guillarmod, M. Recommandations pour la prise en charge des pathologies cervicales. GRSSGO.

[31] The American College of Obstetricians and Gynecologists. http://www.ACOG.org

[32] The American Society for Colposcopy and Cervical Pathology. http://www.asccp.org/Default.aspx 